\title{
Low serum 25-hydroxyvitamin D level predicts progression to type 2 diabetes in individuals with prediabetes but not with normal glucose tolerance
}

\author{
A. Deleskog • A. Hilding • K. Brismar • A. Hamsten • \\ S. Efendic • C.-G. Östenson
}

Received: 14 December 2011 / Accepted: 23 February 2012 / Published online: 17 March 2012

(C) Springer-Verlag 2012

\begin{abstract}
Aims/hypothesis Vitamin D deficiency may increase the risk of type 2 diabetes. We therefore investigated whether serum concentrations of 25-hydroxyvitamin D [25(OH)D] would predict the development of prediabetes (impaired fasting glucose, impaired glucose tolerance or the two combined) and type 2 diabetes, either on their own or when combined with serum concentrations of IGF-1 or IGF-binding protein-1 (IGFBP-1), which may interact with 25(OH)D.

Methods At baseline, participants aged 35-56 years without known type 2 diabetes were examined using OGTTs, 25 $(\mathrm{OH}) \mathrm{D}$ and IGF peptide measurements, and anthropometric and lifestyle data. Participants who had prediabetes or type 2 diabetes at follow-up 8-10 years later were selected as cases; these were then age- and sex-matched to controls with normal glucose tolerance (NGT) at both baseline and follow-up, giving a total of 980 women and 1,398 men.

Results Men but not women in the highest quartile of 25 (OH)D level had a decreased OR for developing type 2 diabetes after adjustment for confounders (OR 0.52, 95\% CI 0.30, 0.90), an effect accounted for by individuals with prediabetes, but not with NGT, at baseline. In both sexes, progression from prediabetes to type 2 diabetes was reduced
\end{abstract}

Electronic supplementary material The online version of this article (doi:10.1007/s00125-012-2529-x) contains peer-reviewed but unedited supplementary material, which is available to authorised users.

A. Deleskog $(\bowtie) \cdot$ A. Hilding $\cdot$ K. Brismar $\cdot$ S. Efendic $\cdot$

C.-G. Östenson

Department of Molecular Medicine and Surgery,

Karolinska Institutet, Karolinska University Hospital, M1:03,

SE-17176 Stockholm, Sweden

e-mail: anna_deleskog@ki.se

A. Hamsten

Center for Molecular Medicine, Karolinska Institutet,

Stockholm, Sweden by about $25 \%$ per $10 \mathrm{nmol} / \mathrm{l}$ increase in $25(\mathrm{OH}) \mathrm{D}$. A high IGFBP-1 value was a better predictor of a reduced risk of type 2 diabetes than high 25(OH)D for both sexes, whereas high IGF-1 concentrations predicted a decreased risk only in men.

Conclusions/interpretation High serum 25(OH)D concentrations predict a reduced risk of type 2 diabetes in individuals with prediabetes, but not NGT. There were no significant interactions between $25(\mathrm{OH}) \mathrm{D}$ and IGFBP-1 or IGF-1 in terms of risk of diabetes. Our data suggest that vitamin D supplementation should be evaluated for the prevention of type 2 diabetes in prediabetic individuals.

Keywords Impaired fasting glucose - Impaired glucose tolerance $\cdot$ Insulin-like growth factors .

Type 2 diabetes · Vitamin D

$\begin{array}{ll}\text { Abbreviations } \\ \text { 25(OH)D } & \text { 25-Hydroxyvitamin D } \\ \text { FHD } & \text { Family history of diabetes } \\ \text { IFG } & \text { Impaired fasting glucose } \\ \text { IGFBP-1 } & \text { Insulin-like growth factor binding protein-1 } \\ \text { IGT } & \text { Impaired glucose tolerance } \\ \text { NGT } & \text { Normal glucose tolerance } \\ \text { VDR } & \text { Vitamin D receptor }\end{array}$

\section{Introduction}

A growing body of evidence from observational studies suggests that low serum concentrations of vitamin $\mathrm{D}$, measured as 25-hydroxyvitamin D [25(OH)D], are associated with type 2 diabetes and the metabolic syndrome, although the relationship has not been shown to be entirely consistent 
(see [1-6] for a review). As it is a major challenge to find strategies for the early detection of individuals at high risk of type 2 diabetes, and thereby possibly novel mechanisms for its prevention and early treatment, a few studies have addressed the issue of whether low serum $25(\mathrm{OH}) \mathrm{D}$ concentrations can predict the development of type 2 diabetes [7-12]. However, some of these reports are limited by, for example, the use of indirect measures or surrogate markers of vitamin D status [11] and type 2 diabetes [9], by a rather small study sample [9] or by an incomplete identification of incident type 2 diabetes $[7,8,10]$. Thus, further long-term prospective studies involving well-characterised cohorts seem warranted to investigate the predictive value of serum 25(OH)D for type 2 diabetes.

Assuming that an inverse association exists between 25 $(\mathrm{OH}) \mathrm{D}$ and risk of type 2 diabetes, the putative mechanism (s) behind such an association need to be elucidated. Studies in both animals and humans have suggested that vitamin D may exert positive effects on insulin secretion and insulin sensitivity, either directly, or indirectly through a modulation of calcium metabolism [13-16]. An alternative link between vitamin $\mathrm{D}$ and glucose homeostasis might be the IGF system [9]. We have shown that low serum levels of IGF-binding protein-1(IGFBP-1) in men and women with normal glucose tolerance (NGT) strongly predict risk of type 2 diabetes and prediabetes (impaired fasting glucose [IFG], impaired glucose tolerance [IGT] or the two combined) at a follow-up 8-10 years later [17, 18]. In addition, a combination of high concentrations of 25(OH)D and IGF-1 has been associated with a low risk of the metabolic syndrome [19].

The primary aim of this study was to investigate whether the development of prediabetes (IFG or IGT) and type 2 diabetes can be predicted by serum $25(\mathrm{OH}) \mathrm{D}$ concentration. For this purpose, we analysed $25(\mathrm{OH}) \mathrm{D}$ concentrations in a well-characterised cohort of 2,378 middle-aged women and men with either NGT or prediabetes at a baseline investigation in relation to their glucometabolic status (NGT, prediabetes or type 2 diabetes) at a follow-up investigation 8-10 years later. Moreover, associations between serum 25(OH)D concentrations and prediabetes were evaluated using data from the baseline investigation. Combinations of 25(OH)D and IGF-1 or IGFBP-1, respectively, in association with prediabetes and type 2 diabetes were studied both at baseline and in the prospective investigation.

\section{Methods}

Study population The study population consisted of participants in an epidemiological survey, the Stockholm Diabetes Prevention Program, described elsewhere [20]. In brief, women and men aged 35-56 years without known diabetes participated in the baseline study over the period 1992-
1998. The follow-up examination, $8-10$ years later, included individuals who at baseline had either NGT or prediabetes (including IFG and IGT), but not those who had newly diagnosed type 2 diabetes at the baseline examination. A health examination, including measurements of weight, height and BP, and an OGTT were performed, and questionnaires covering lifestyle factors were answered at baseline and at follow-up.

Associations between 25(OH)D concentration and abnormal glucose regulation were evaluated in a nested casecontrol setting. Thus, serum concentrations of $25(\mathrm{OH}) \mathrm{D}$ were measured at baseline in all participants with abnormal glucose regulation, i.e. either prediabetes or type 2 diabetes at follow-up (490 women and 699 men), and in an equal number of participants, randomly selected within sex but pair-matched by exact age, from the group who had NGT at both baseline and follow-up.

Analyses were performed in three ways, two prospective and one cross-sectional. In prospective study 1 , cases were individuals who had progressed from NGT at baseline to either prediabetes (304 women, 428 men) or type 2 diabetes (47 women, $87 \mathrm{men}$ ) at follow-up, or from prediabetes at baseline to type 2 diabetes (53 women, 92 men) at followup. The controls were 404 women and 607 men with NGT at both baseline and follow-up. In prospective study 2 , which was a subset of prospective study 1 , all cases had NGT at baseline and progressed to either prediabetes (304 women, 428 men) or type 2 diabetes ( 47 women, 87 men) at followup; the controls were 351 women and 515 men with NGT at both baseline and follow-up.

A cross-sectional study was also performed in which the cases were all individuals who had prediabetes at baseline, including not only those who progressed to type 2 diabetes, but also those who also had prediabetes at follow-up, a total of 139 women and 184 men. In this analysis, the controls were all participants with NGT at baseline, irrespective of glucose tolerance at follow-up, giving a total of 841 women and 1,214 men.

The investigation was approved by the ethics committee of Karolinska Institutet, and was carried out in accordance with the principles of the Declaration of Helsinki. All participants gave their informed consent.

Seasonal variations in serum $25(\mathrm{OH})$ D concentration There was a seasonal variation in concentrations of $25(\mathrm{OH}) \mathrm{D}$. To adjust for this, the months were categorised into four quarters: (1) November-January, (2) February-April, (3) MayJuly, and (4) August-October. According to sunlight exposure in Sweden, quarter 1 has the fewest sun hours. Linear regression analyses were performed with $25(\mathrm{OH}) \mathrm{D}$ as the dependent variable and the four quarters, coded as dummy variables using quarter 1 as the reference, as independent variables. Estimated $\beta$-coefficients were then used to adjust all individual $25(\mathrm{OH}) \mathrm{D}$ values for seasonal variation. 
Classification of glucose tolerance The $75 \mathrm{~g}$ OGTT was performed at baseline and at follow-up examination, and glucose regulation was defined according to American Diabetes Association guidelines [21], using a fasting serum glucose value of $\geq 5.6 \mathrm{mmol} / 1$ as the cut-off value for IFG.

Classification of established risk factors for diabetes and potential confounders Physical activity during leisure hours was based on four response alternatives and categorised into three groups: low (sedentary), middle (moderate activity) and high (regular exercise and training). BMI was also divided into three groups $\left(<25.0,25.0-29.9\right.$ and $\left.\geq 30.0 \mathrm{~kg} / \mathrm{m}^{2}\right)$. Waist circumference was categorised into three $(<80,80-87>87 \mathrm{~cm}$ for women, and $<94,94-101$ and $>101 \mathrm{~cm}$ for men). Tobacco use (including smoking and snuff) was described as either never/former use or current tobacco use. Family history of diabetes (FHD) was designated positive when at least one first-degree (parents or siblings) or two second-degree relatives (grandparents, uncles or aunts) had been diagnosed with diabetes, or negative when no close relative had diabetes.

Socioeconomic position, based on self-reported occupation and classified according to the standard system from Statistics Sweden, was categorised into four groups (high, middle, low and self-employed). Education comprised three categories: low (elementary school), middle (senior high school, or technical and vocational school) and high (college or university). High BP was defined as a systolic BP $\geq 140 \mathrm{mmHg}$ and/or a diastolic $\mathrm{BP} \geq 90 \mathrm{mmHg}$ and/or the use of antihypertensive treatment.

Assays Serum concentrations of $25(\mathrm{OH}) \mathrm{D}$ were determined by a chemiluminescence immunoassay (DiaSorin Inc., Stillwater, MN, USA) measuring both $25(\mathrm{OH}) \mathrm{D}_{3}$ and $25(\mathrm{OH}) \mathrm{D}_{2}$ with intra- and interassay $\mathrm{CVs}$ of $5 \%$ and $8 \%$, respectively. Serum IGFBP-1 was measured using an inhouse RIA with intra- and inter-assay $(\mathrm{CV})$ values of $3 \%$ and $10 \%$, respectively. IGF-1 was measured in serum by RIA after acid-ethanol extraction and cryoprecipitation, using des(1-3)IGF-1 as a tracer to minimise interference from IGFBPs. Intra- and interassay CVs were $4 \%$ and $11 \%$, respectively. Venous serum glucose was assayed using the glucose oxidase method (Yellow Springs Glucose Analyzer, Yellow Springs, OH, USA).

Statistical analysis Seasonally adjusted 25(OH)D values were used in all analyses, either categorised into quartiles or used as a continuous variable and reported per increment of $10 \mathrm{nmol} / \mathrm{l}$. Categorisation into quartiles was performed according to the distribution between all participants, women and men combined $(n=2,378)$. Variables not normally distributed (IGFBP-1 and IGF-1) were log-transformed prior to analysis. Differences between groups were analysed by ANOVA for trend, and unpaired $t$ test or $\chi^{2}$-square test for continuous and categorical data, respectively. ORs together with 95\% CIs were calculated in multiple logistic regression analysis to explore the association between serum $25(\mathrm{OH}) \mathrm{D}$ concentrations and abnormal glucose regulation.

Potential confounders (physical activity during leisure time, BMI, waist, tobacco use, FHD, socioeconomic position, education and BP) were tested separately in logistic regression models including the exposure variable and age. The change-in-estimate method was used, meaning that variables that contributed to at least a $10 \%$ change to the age-adjusted crude estimate in any of the outcome measures were included in the final multiadjusted model. Waist and BMI had similar influence on the crude estimates, so BMI was chosen for the final model. Thus, two logistic regression models are given: model 1 adjusted for age (and sex when combining male and female participants), and model 2 adjusted for age, BMI, FHD, physical activity and BP (and sex if applicable).

When categories of $25(\mathrm{OH}) \mathrm{D}$ were used in the logistic regression analyses, tests of linear trend were conducted by assigning median values of $25(\mathrm{OH}) \mathrm{D}$ in quartiles as a continuous variable. Since no statistical interaction was found between sex and $25(\mathrm{OH}) \mathrm{D}$ for any of the outcome measures, analyses are reported not only separately, but also for women and men combined. Analyses of combinations of $25(\mathrm{OH})$ D and IGF-I or IGFBP-1 were performed with the variables dichotomised at their medians, and statistical interaction was tested by including a product term into the regression models. Only participants for whom there were data on all variables were included in the study.

The analyses were performed using SAS statistical package version 9.2 for Windows (SAS Institute, Cary, NC, USA).

\section{Results}

Baseline characteristics according to quartiles of 25(OH) $D$ Women and men in the highest $25(\mathrm{OH}) \mathrm{D}$ quartile(s) were more physically active, had lower $2 \mathrm{~h}$ glucose levels during the OGTT and a lower prevalence of prediabetes, were less obese, with a lower BMI and smaller waist circumference, and had higher serum IGFBP-1 and IGF-1 levels compared with participants in the lower quartiles of the seasonally adjusted 25(OH)D concentrations (see electronic supplementary material [ESM] Table 1). In addition, women and men in the lowest quartile used more tobacco. There was no association between FHD and 25(OH)D concentrations. Furthermore, seasonally adjusted $25(\mathrm{OH}) \mathrm{D}$ concentrations were lower in women than in men (mean $57.0 \mathrm{nmol} / 1,95 \%$ CI $55.9,58.1$ vs $61.2 \mathrm{nmol} / 1,95 \%$ CI $60.2,62.2 ; p<0.0001$ ).

Baseline characteristics and glucose tolerance at followup Among all cases who had NGT or prediabetes at baseline 
and progressed to either prediabetes or type 2 diabetes at follow-up, both women and men had a higher prevalence of FHD, higher frequencies of hypertension, higher BMI and waist circumference, more prevalent current tobacco use, and lower concentrations of adjusted $25(\mathrm{OH}) \mathrm{D}$ and lower IGFBP-1 levels compared with controls with NGT at both baseline and follow-up (Table 1). In addition, women with prediabetes or type 2 diabetes at follow-up were less physically active and had higher levels of IGF-1, whereas the corresponding men had lower levels of IGF-1 than NGT participants.

Similar differences compared with controls were observed when analysing only data from participants who had NGT at baseline, although in men the levels of 25 (OHD) did not differ (Table 1).

Prospective studies of the association of $25(\mathrm{OH}) \mathrm{D}$ concentration with development of prediabetes and type 2 diabetes In prospective study 1 (Table 2), participants who had NGT or prediabetes at baseline and were in the highest seasonally adjusted quartile of $25(\mathrm{OH}) \mathrm{D}$ concentration had a reduced risk (OR $0.64, \mathrm{CI} 0.50,0.82)$ of progressing to prediabetes or type 2 diabetes compared with those in the lowest quartile. Yet after full adjustment for confounders (age, BMI, BP, FHD and physical activity), the reduction in risk did not remain. When analysing progression only to type 2 diabetes from NGT or prediabetes, a reduced risk (OR 0.58, CI 0.37, 0.90) was found after full adjustment. Moreover, for progression from prediabetes to type 2 diabetes, there was an even greater reduction in risk (OR 0.38, CI $0.21,0.71)$, the reduction in risk being $23 \%$ for each $10 \mathrm{nmol} / 1$ increase in $25(\mathrm{OH}) \mathrm{D}$.

In analyses stratified for sex, women in the highest quartile of $25(\mathrm{OH}) \mathrm{D}$ concentration had a decreased age-adjusted OR for progress to either prediabetes or type 2 diabetes compared with controls (OR 0.56, CI 0.38, 0.84; Table 2), but this association did not persist after full adjustment. The results were similar when analysing women progressing from NGT or prediabetes to type 2 diabetes. However, in women who progressed from prediabetes to type 2 diabetes, the OR was 0.73 (CI $0.58,0.86$ ) for a $10 \mathrm{nmol} / 1$ increase in $25(\mathrm{OH}) \mathrm{D}$ concentrations after adjustment (Table 2). For men in the highest quartile of the $25(\mathrm{OH}) \mathrm{D}$ distribution, there was also an age-adjusted reduced OR (OR 0.68, CI 0.49, 0.95), but, as in women, this association did not persist after full adjustment. However, in men belonging to the highest serum 25(OH)D quartile, there was a decrease in OR (OR 0.40, CI 0.19, 0.85) for progression from prediabetes to type 2 diabetes. Similar to the effect in women, a $10 \mathrm{nmol} / 1$ increase in $25(\mathrm{OH}) \mathrm{D}$ concentration reduced the risk of diabetes in men with prediabetes by $21 \%$ (OR 0.79 , CI $0.68,0.93)$.

In prospective study 2 (ESM Table 2), analyses were performed on participants progressing from NGT to either prediabetes, type 2 diabetes or prediabetes and type 2 diabetes combined. However, after full adjustment, no associations were found with $25(\mathrm{OH}) \mathrm{D}$ for any of the outcomes, either for the two sexes separately or when they were combined.

The association between combinations of baseline serum concentrations of 25(OH)D and IGFBP-1 or IGF-1, respectively, and type 2 diabetes at follow-up was analysed in participants with NGT or prediabetes at baseline who developed type 2 diabetes at follow-up (Fig. 1). In both women and men, high levels of IGFBP-1 (above the median) significantly predicted a reduced risk of type 2 diabetes, while at high concentrations of $25(\mathrm{OH}) \mathrm{D}$ (above the median), there was only a tendency towards a risk reduction. In combinations, no significant interaction term between categories of 25(OH)D and IGFBP-1 was found either for women $(p=0.168)$ or for men $(p=0.364)$. Although high levels of IGFBP-1 further reduced the risk of developing type 2 diabetes, this reduction was similar regardless of 25 $(\mathrm{OH}) \mathrm{D}$ concentration. Moreover, only in participants with high IGFBP-1 levels was the risk of type 2 diabetes significantly reduced compared with those having low levels of both variables. In women, there was no difference in risk of type 2 diabetes according to IGF-1 levels (above or below the median value), and the risk was not further significantly influenced in those with high $25(\mathrm{OH}) \mathrm{D}$ concentrations $(p=$ 0.743 for the interaction term; Fig. 1). In partial contrast, men with a high (above the median) IGF-1 level showed a reduced risk of type 2 diabetes irrespective of $25(\mathrm{OH}) \mathrm{D}$ concentrations, and no interaction between IGF-1 and 25 $(\mathrm{OH}) \mathrm{D}$ was observed $(p=0.250)$.

Cross-sectional study of the association between 25(OH)D concentrations and prediabetes At baseline, participants with prediabetes had a higher prevalence of positive FHD and of hypertension, a higher BMI and waist circumference, and lower serum levels of IGFBP-1 and seasonally adjusted 25(OH)D compared with controls with NGT (ESM Table 3). Men but not women with prediabetes had lower serum IGF1 levels. In addition, prediabetic women but not men were less physically active. In the logistic regression analyses of all participants, those in the two highest quartiles of $25(\mathrm{OH})$ D showed a decreased association of $25(\mathrm{OH}) \mathrm{D}$ with prediabetes after full adjustment (OR 0.49, CI 0.34, 0.72, and OR 0.58 , CI $0.41,0.83$, respectively; Table 3 ). This was accounted for by significant associations in men (OR 0.41, CI $0.25,0.68$, and OR 0.57 , CI 0.36, 0.91, respectively) but not in women. For each $10 \mathrm{nmol} / \mathrm{l}$ increase in serum $25(\mathrm{OH}) \mathrm{D}$, the association with prediabetes was decreased by $18 \%$ in men $(p<$ $0.001)$ and $11 \%$ in women $(0.051)$.

In women, there were no significant associations between dichotomised serum concentrations of 25(OH)D, IGFBP-1 or IGF-1 and prediabetes at baseline (Fig. 2). However, in 
Table 1 Baseline characteristics for the prospective studies

\begin{tabular}{|c|c|c|c|c|c|c|}
\hline \multirow[t]{2}{*}{ Variable } & \multicolumn{3}{|l|}{ Prospective study $1^{\mathrm{a}}$} & \multicolumn{3}{|l|}{ Prospective study $2^{\mathrm{b}}$} \\
\hline & $\begin{array}{l}\text { NGT at baseline- } \\
\text { NGT at follow-up }\end{array}$ & $\begin{array}{l}\text { NGT or prediabetes at } \\
\text { baseline-prediabetes or } \\
\text { type } 2 \text { diabetes at follow-up }\end{array}$ & $p$ value $^{\mathrm{c}}$ & $\begin{array}{l}\text { NGT at baseline-- } \\
\text { NGT at follow-up }\end{array}$ & $\begin{array}{l}\text { NGT at baseline- } \\
\text { prediabetes or type } \\
2 \text { diabetes at follow-up }\end{array}$ & $p$ value ${ }^{\mathrm{c}}$ \\
\hline Women $(n)$ & 404 & 404 & & 351 & 351 & \\
\hline FHD, positive & $212(52.5)$ & 277 (68.6) & $<0.001$ & $183(52.1)$ & $232(66.1)$ & $<0.001$ \\
\hline \multicolumn{7}{|l|}{ Physical activity } \\
\hline Sedentary & $43(10.6)$ & $66(16.3)$ & & $41(11.7)$ & $54(15.4)$ & \\
\hline Moderate exercise & $218(54.0)$ & $245(60.6)$ & & $187(53.3)$ & $217(61.8)$ & \\
\hline Regular exercise & $143(35.4)$ & $93(23.0)$ & $<0.001$ & $123(35.0)$ & $80(22.8)$ & 0.001 \\
\hline Tobacco use, current & $111(27.5)$ & $141(34.9)$ & 0.023 & $98(27.9)$ & $124(35.3)$ & 0.035 \\
\hline Hypertension, yes & $57(14.1)$ & $128(31.7)$ & $<0.001$ & $54(15.4)$ & $103(29.3)$ & $<0.001$ \\
\hline \multicolumn{7}{|l|}{ Glucose tolerance at baseline } \\
\hline NGT & $404(100.0)$ & $351(86.9)$ & & $351(100.0)$ & $351(100.0)$ & \\
\hline Prediabetes & $0(0.0)$ & $53(13.1)$ & NA & $0(0.0)$ & $0(0.0)$ & NA \\
\hline Age (years) & $48.9(48.5,49.3)$ & $48.8(48.4,49.2)$ & 0.925 & $48.8(48.3,49.2)$ & $48.7(48.3,49.2)$ & 0.919 \\
\hline BMI $\left(\mathrm{kg} / \mathrm{m}^{2}\right)$ & $24.3(24.0,24.7)$ & $27.9(27.4,28.4)$ & $<0.001$ & $24.4(24.0,24.8)$ & $27.5(27.0,28.0)$ & $<0.001$ \\
\hline Waist circumference $(\mathrm{cm})$ & $78(77,79)$ & $87(86,88)$ & $<0.001$ & $78(77,79)$ & $86(85,87)$ & $<0.001$ \\
\hline $\begin{array}{l}25(\mathrm{OH}) \mathrm{D}, \text { seasonally } \\
\text { adjusted }(\mathrm{nmol} / \mathrm{l})\end{array}$ & $59(57,61)$ & $55(54,57)$ & 0.001 & $59(57,61)$ & $56(54,58)$ & 0.027 \\
\hline IGFBP-1 $(\mu \mathrm{g} /)^{\mathrm{d}}$ & $50(47,52)$ & $34(32,36)$ & $<0.001$ & $49(47,52)$ & $34(32,36)$ & $<0.001$ \\
\hline IGF-I $\left(\mu \mathrm{g} / \mathrm{l}^{\mathrm{d}}\right.$ & $174(170,179)$ & $185(180,190)$ & 0.002 & $176(171,182)$ & $186(180,191)$ & 0.017 \\
\hline Men $(n)$ & 607 & 607 & & 515 & 515 & \\
\hline FHD, positive & $281(46.3)$ & $371(61.1)$ & $<0.001$ & $234(45.4)$ & $312(60.6)$ & $<0.001$ \\
\hline \multicolumn{7}{|l|}{ Physical activity } \\
\hline Sedentary & $60(9.9)$ & $71(11.7)$ & & $50(9.7)$ & $58(11.3)$ & \\
\hline Moderate exercise & $302(49.8)$ & $329(54.2)$ & & $261(50.7)$ & $278(54.0)$ & \\
\hline Regular exercise & $245(40.4)$ & $207(34.1)$ & 0.072 & $204(39.6)$ & $179(34.7)$ & 0.252 \\
\hline Tobacco use, current & $212(34.9)$ & $256(42.2)$ & 0.010 & $181(35.2)$ & $215(41.8)$ & 0.029 \\
\hline Hypertension, yes & $134(22.1)$ & $234(38.5)$ & $<0.001$ & $120(23.3)$ & $182(35.3)$ & $<0.001$ \\
\hline \multicolumn{7}{|l|}{ Glucose tolerance at baseline } \\
\hline NGT & $607(100.0)$ & $515(84.8)$ & & $515(100.0)$ & $515(100.0)$ & \\
\hline Prediabetes & $0(0.0)$ & $92(15.2)$ & NA & $0(0.0)$ & $0(0.0)$ & NA \\
\hline Age (years) & $47.5(47.2,47.9)$ & $47.5(47.2,47.9)$ & 0.956 & $47.4(47.0,47.8)$ & $47.4(47.0,47.8)$ & 0.958 \\
\hline BMI $\left(\mathrm{kg} / \mathrm{m}^{2}\right)$ & $25.4(25.2,25.6)$ & $27.4(27.1,27.7)$ & $<0.001$ & $25.3(25.1,25.6)$ & $27.1(26.8,27.4)$ & $<0.001$ \\
\hline Waist circumference $(\mathrm{cm})$ & $91(91,92)$ & $95(95,96)$ & $<0.001$ & $91(91,92)$ & $95(94,95)$ & $<0.001$ \\
\hline $\begin{array}{l}25(\mathrm{OH}) \mathrm{D} \text {, seasonally } \\
\text { adjusted }(\mathrm{nmol} / \mathrm{l})\end{array}$ & $63(61,64)$ & $60(59,62)$ & 0.052 & $62(60,64)$ & $61(60,63)$ & 0.606 \\
\hline IGFBP-1 $(\mu \mathrm{g} / 1)^{\mathrm{d}}$ & $31(29,32)$ & $18(17,19)$ & $<0.001$ & $31(29,33)$ & $19(17,29)$ & $<0.001$ \\
\hline IGF-I $(\mu \mathrm{g} / 1)^{\mathrm{d}}$ & $199(195,204)$ & $191(187,195)$ & 0.004 & $199(184,204)$ & $193(189,197)$ & 0.089 \\
\hline
\end{tabular}

Data are expressed as mean $(95 \% \mathrm{CI})$ or ${ }^{\mathrm{d}}$ geometrical mean $(95 \% \mathrm{CI})$ for continuous variables, and as number (\%) for categorical variables. Participants were selected as controls or cases according to a combination of glucose tolerance at baseline and follow-up

${ }^{a}$ Cases had progressed in terms of glucose tolerance at follow-up, from NGT at baseline to either prediabetes or type 2 diabetes at follow-up, or from prediabetes at baseline to type 2 diabetes at follow-up. Controls had NGT at both baseline and follow-up

${ }^{\mathrm{b}}$ Cases had all NGT at baseline and progressed to either prediabetes or type 2 diabetes at follow-up. Controls had NGT at both baseline and follow-up ${ }^{\mathrm{c}}$ Comparisons between cases and controls; $p$ values were derived from the $\chi^{2}$ test for categorical variables and from unpaired $t$ tests for continuous variables

NA, not applicable

men with high levels of IGFBP-1 (above the median), the ORs associated with prediabetes were further reduced, but to a similar extent in participants with low and with high concentrations of $25(\mathrm{OH}) \mathrm{D}(p=0.745$ for the interaction). 
Table 2 Prospective study 1

\begin{tabular}{|c|c|c|c|c|c|c|c|c|c|c|c|c|c|}
\hline \multirow[t]{3}{*}{ 25(OH)D concentration } & \multirow{3}{*}{$\begin{array}{l}\text { Controls } \\
n\end{array}$} & \multicolumn{12}{|l|}{ Cases } \\
\hline & & \multicolumn{4}{|c|}{$\begin{array}{l}\text { Progress from NGT to prediabetes or } \\
\text { to } \mathrm{T} 2 \mathrm{D} \text { or from prediabetes to } \mathrm{T} 2 \mathrm{D}\end{array}$} & \multicolumn{4}{|c|}{$\begin{array}{l}\text { Progress from NGT to T2D } \\
\text { or from prediabetes to T2D }\end{array}$} & \multicolumn{4}{|c|}{$\begin{array}{l}\text { Progress from prediabetes } \\
\text { to } \mathrm{T} 2 \mathrm{D}\end{array}$} \\
\hline & & $n$ & OR & $95 \%$ CI & $p$ value $^{\mathrm{a}}$ & $n$ & OR & $95 \% \mathrm{CI}$ & $n$ value $^{\mathrm{a}}$ & $n$ & OR & $95 \%$ CI & $p$ value ${ }^{\mathrm{a}}$ \\
\hline \multicolumn{14}{|l|}{ Women } \\
\hline \multicolumn{14}{|l|}{ Model 1} \\
\hline Quartile 1 & 98 & 128 & 1.00 & & & 41 & 1.00 & & & 25 & 1.00 & & \\
\hline Quartile 2 & 106 & 119 & 0.86 & $0.59,1.25$ & & 32 & 0.72 & $0.42,1.24$ & & 20 & 0.74 & $0.39,1.42$ & \\
\hline Quartile 3 & 102 & 85 & 0.64 & $0.43,0.94$ & & 12 & 0.28 & $0.14,0.57$ & & 3 & 0.12 & $0.04,0.41$ & \\
\hline Quartile 4 & 98 & 72 & 0.56 & $0.38,0.84$ & 0.002 & 15 & 0.37 & $0.19,0.70$ & $<0.001$ & 5 & 0.20 & $0.07,0.55$ & $<0.001$ \\
\hline Continuous, per $10 \mathrm{nmol} / 1$ & 404 & 404 & 0.88 & $0.81,0.95$ & 0.001 & 100 & 0.76 & $0.66,0.87$ & $<0.001$ & 53 & 0.66 & $0.54,0.80$ & $<0.001$ \\
\hline \multicolumn{14}{|l|}{ Model 2} \\
\hline Quartile 1 & 98 & 128 & 1.00 & & & 41 & 1.00 & & & 25 & 1.00 & & \\
\hline Quartile 2 & 106 & 119 & 0.89 & $0.59,1.35$ & & 32 & 0.92 & $0.48,1.75$ & & 20 & 0.93 & $0.43,1.99$ & \\
\hline Quartile 3 & 102 & 85 & 0.72 & $0.47,1.11$ & & 12 & 0.44 & $0.20,0.97$ & & 3 & 0.15 & $0.04,0.55$ & \\
\hline Quartile 4 & 98 & 72 & 0.82 & $0.53,1.28$ & 0.255 & 15 & 0.79 & $0.36,1.73$ & 0.234 & 5 & 0.38 & $0.13,1.17$ & 0.010 \\
\hline Continuous, per $10 \mathrm{nmol} / 1$ & 404 & 404 & 0.95 & $0.87,1.04$ & 0.239 & 100 & 0.88 & $0.75,1.04$ & 0.131 & 53 & 0.73 & $0.58,0.92$ & 0.009 \\
\hline \multicolumn{14}{|c|}{ Men } \\
\hline \multicolumn{14}{|l|}{ Model 1} \\
\hline Quartile 1 & 117 & 147 & 1.00 & & & 53 & 1.00 & & & 27 & 1.00 & & \\
\hline Quartile 2 & 145 & 145 & 0.79 & $0.57,1.11$ & & 46 & 0.68 & $0.43,1.08$ & & 30 & 0.85 & $0.47,1.51$ & \\
\hline Quartile 3 & 163 & 157 & 0.76 & $0.55,1.06$ & & 46 & 0.59 & $0.37,0.94$ & & 20 & 0.48 & $0.26,0.91$ & \\
\hline Quartile 4 & 182 & 158 & 0.68 & $0.49,0.95$ & 0.028 & 34 & 0.38 & $0.23,0.62$ & $<0.001$ & 15 & 0.31 & $0.16,0.62$ & $<0.001$ \\
\hline Continuous, per $10 \mathrm{nmol} / 1$ & 607 & 607 & 0.94 & $0.87,1.00$ & 0.050 & 179 & 0.83 & $0.75,0.91$ & $<0.001$ & 92 & 0.75 & $0.66,0.86$ & $<0.001$ \\
\hline \multicolumn{14}{|c|}{ Model 2} \\
\hline Quartile 1 & 117 & 147 & 1.00 & & & 53 & 1.00 & & & 27 & 1.00 & & \\
\hline Quartile 2 & 145 & 145 & 0.75 & $0.53,1.07$ & & 46 & 0.70 & $0.42,1.17$ & & 30 & 0.84 & $0.44,1.59$ & \\
\hline Quartile 3 & 163 & 157 & 0.81 & $0.57,1.15$ & & 46 & 0.66 & $0.40,1.11$ & & 20 & 0.53 & $0.26,1.08$ & \\
\hline Quartile 4 & 182 & 158 & 0.80 & $0.56,1.14$ & 0.346 & 34 & 0.52 & $0.30,0.90$ & 0.022 & 15 & 0.40 & $0.19,0.85$ & 0.009 \\
\hline Continuous, per $10 \mathrm{nmol} / 1$ & 607 & 607 & 0.98 & $0.92,1.05$ & 0.549 & 179 & 0.89 & $0.80,0.99$ & 0.035 & 92 & 0.79 & $0.68,0.93$ & 0.004 \\
\hline \multicolumn{14}{|c|}{ Women and men } \\
\hline \multicolumn{14}{|l|}{ Model 1} \\
\hline Quartile 1 & 215 & 275 & 1.00 & & & 94 & 1.00 & & & 52 & 1.00 & & \\
\hline Quartile 2 & 251 & 264 & 0.82 & $0.64,1.05$ & & 78 & 0.69 & $0.49,0.99$ & & 50 & 0.79 & $0.51,1.22$ & \\
\hline Quartile 3 & 265 & 242 & 0.71 & $0.55,0.91$ & & 58 & 0.48 & $0.33,0.70$ & & 23 & 0.34 & $0.20,0.57$ & \\
\hline Quartile 4 & 280 & 230 & 0.64 & $0.50,0.82$ & $<0.001$ & 49 & 0.37 & $0.25,0.55$ & $<0.001$ & 20 & 0.27 & $0.15,0.46$ & $<0.001$ \\
\hline Continuous, per $10 \mathrm{nmol} / 1$ & 1,011 & 1,011 & 0.92 & $0.88,0.96$ & $<0.001$ & 279 & 0.80 & $0.74,0.87$ & $<0.001$ & 145 & 0.72 & $0.65,0.81$ & $<0.001$ \\
\hline \multicolumn{14}{|c|}{ Model 2} \\
\hline Quartile 1 & 215 & 275 & 1.00 & & & 94 & 1.00 & & & 52 & 1.00 & & \\
\hline Quartile 2 & 251 & 264 & 0.81 & $0.62,1.05$ & & 78 & 0.76 & $0.51,1.13$ & & 50 & 0.85 & $0.52,1.38$ & \\
\hline Quartile 3 & 265 & 242 & 0.78 & $0.59,1.02$ & & 58 & 0.59 & $0.38,0.90$ & & 23 & 0.39 & $0.21,0.70$ & \\
\hline Quartile 4 & 280 & 230 & 0.80 & $0.62,1.06$ & 0.146 & 49 & 0.58 & $0.37,0.90$ & 0.008 & 20 & 0.38 & $0.21,0.71$ & $<0.001$ \\
\hline Continuous, per $10 \mathrm{nmol} / 1$ & 1,011 & 1,011 & 0.97 & $0.92,1.02$ & 0.241 & 279 & 0.88 & $0.81,0.97$ & 0.007 & 145 & 0.77 & $0.68,0.88$ & $<0.001$ \\
\hline
\end{tabular}

ORs for increasing values of $25(\mathrm{OH}) \mathrm{D}$ in association with the development of prediabetes or type 2 diabetes (T2D) at follow-up. Cases are participants who progressed either from NGT at baseline to prediabetes or T2D at follow-up, or from prediabetes at baseline to T2D at follow-up. Controls had NGT at both baseline and follow-up

$25(\mathrm{OH}) \mathrm{D}$, seasonally adjusted values: quartile $1,<46.2 \mathrm{nmol} / 1$; quartile $2,46.2-58.0 \mathrm{nmol} / \mathrm{l}$; quartile $3,58.1-71.0 \mathrm{nmol} / 1$; quartile $4,>71.0 \mathrm{nmol} / 1$ Model 1, adjusted for age (continuous) and sex if appropriate; model 2, adjusted for age, BMI (<25.0, 25.0-29.9 or $\left.\geq 30.0 \mathrm{~kg} / \mathrm{m}^{2}\right)$, FHD (yes $/ \mathrm{no}$ ), physical activity during leisure time (sedentary, moderate exercise, regular exercise), BP (normal BP and no hypertension treatment vs high BP and/ or hypertension treatment) and sex if appropriate

${ }^{\mathrm{a}} p$ value for trend if $25(\mathrm{OH}) \mathrm{D}$ is a categorical variable 


\section{a}

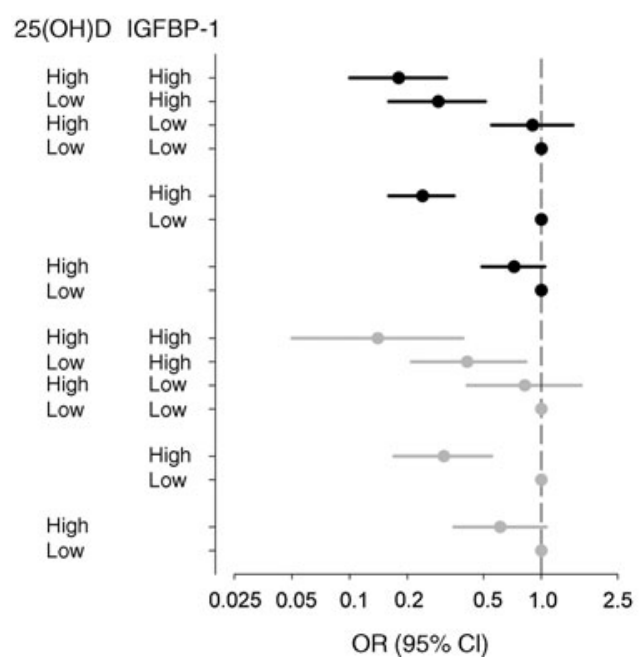

Fig. 1 Baseline serum levels of 25(OH)D and baseline serum levels of IGFBP-1 (a) or IGF-I (b), separately and in combination, associated with the development of type 2 diabetes at follow-up in women (grey lines) and men (black lines). Cases are individuals who had either NGT or prediabetes at baseline and developed type 2 diabetes at follow-up, whereas controls had NGT at both baseline and follow-up (prospective study 1 ). Low, < median; high, $\geq$ median. The seasonally adjusted

Combining categories of $25(\mathrm{OH}) \mathrm{D}$ and IGF-I in men revealed an interaction $(p=0.038)$, indicating that high levels of IGF-I decreased the OR associated with prediabetes in men with low levels of $25(\mathrm{OH}) \mathrm{D}$, whereas the reduced $\mathrm{OR}$ in men with high levels of 25(OH)D was observed irrespective of IGF-I levels.

\section{Discussion}

We found that participants with high concentrations of serum $25(\mathrm{OH}) \mathrm{D}$ showed a reduced prevalence of prediabetes in the cross-sectional study, and that high concentrations of serum $25(\mathrm{OH}) \mathrm{D}$ in participants with prediabetes at baseline predicted a decreased risk of progressing to type 2 diabetes $8-10$ years later. Conversely, low serum $25(\mathrm{OH}) \mathrm{D}$ was associated with increased risk of type 2 diabetes in prediabetic individuals. Notably, in persons with NGT at baseline, high $25(\mathrm{OH}) \mathrm{D}$ concentrations did not predict a significantly reduced risk of progressing to either prediabetes or type 2 diabetes. When analysing whether the associations with 25 $(\mathrm{OH}) \mathrm{D}$ were related to sex, it appeared in the cross-sectional study that they were significant only in men after controlling for confounders. It is noteworthy, however, that in both men and women with prediabetes at baseline, the risk of diabetes at follow-up was significantly decreased, by $21 \%$ and $27 \%$, respectively, for every $10 \mathrm{nmol} / 1$ increase in $25(\mathrm{OH}) \mathrm{D}$.

Our study has several strengths. First, in addition to the baseline investigation, the study has a prospective design in which cases with prediabetes and type 2 diabetes at follow- b

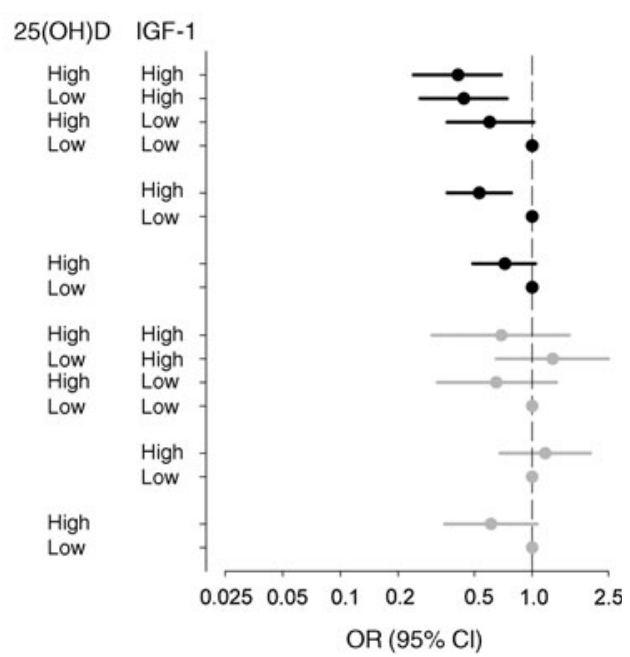

median value for $25(\mathrm{OH}) \mathrm{D}$ was $58.1 \mathrm{nmol} / 1$ for both women and men; the median value of IGFBP-1 for women was $43 \mu \mathrm{g} / 1$ and for men was $25 \mu \mathrm{g} / \mathrm{l}$; and the median value of IGF-I was $192 \mu \mathrm{g} / \mathrm{l}$ for both women and men. Logistic regression was performed. The data are expressed as OR and 95\% CI, adjusted for age, BMI, FHD, physical activity and BP measured at baseline

up were matched by age and sex to individuals who had NGT at both baseline and follow-up. Second, the participants were not aware of having diabetes or prediabetes when the exposure data were recorded, and thus the disease status was not likely to affect their behaviour or lifestyle. Third, the study sample was well-characterised, and adjustment for potential confounders was possible.

The positive association in the cross-sectional study between prediabetes and low serum $25(\mathrm{OH}) \mathrm{D}$ concentrations is in agreement with data from a recent US investigation [22]. Furthermore, similar to our study, the association was independent of confounders such as BMI and BP. In more general terms, a recent review of the role of vitamin $\mathrm{D}$ in prediabetes found that most cross-sectional and prospective studies in various populations demonstrate an inverse association between serum $25(\mathrm{OH}) \mathrm{D}$ concentrations and IGT, fasting plasma glucose, the metabolic syndrome and the incidence of prediabetes [23]. In addition, participants in the highest quartile of 25(OH)D were more physically active, had lower $2 \mathrm{~h}$ glucose levels, were less obese and had a smaller waist circumference compared with participants in the lower quartiles. These findings are consistent with previous cross-sectional studies in which vitamin D deficiency has been associated with other important risk factors for diabetes [24].

The effect of 25(OH)D concentrations on the risk of developing type 2 diabetes was detected in individuals with prediabetes and not with NGT at baseline, suggesting that this effect is not strong enough to affect the development of IGT or IFG. Instead, established risk factors such as 


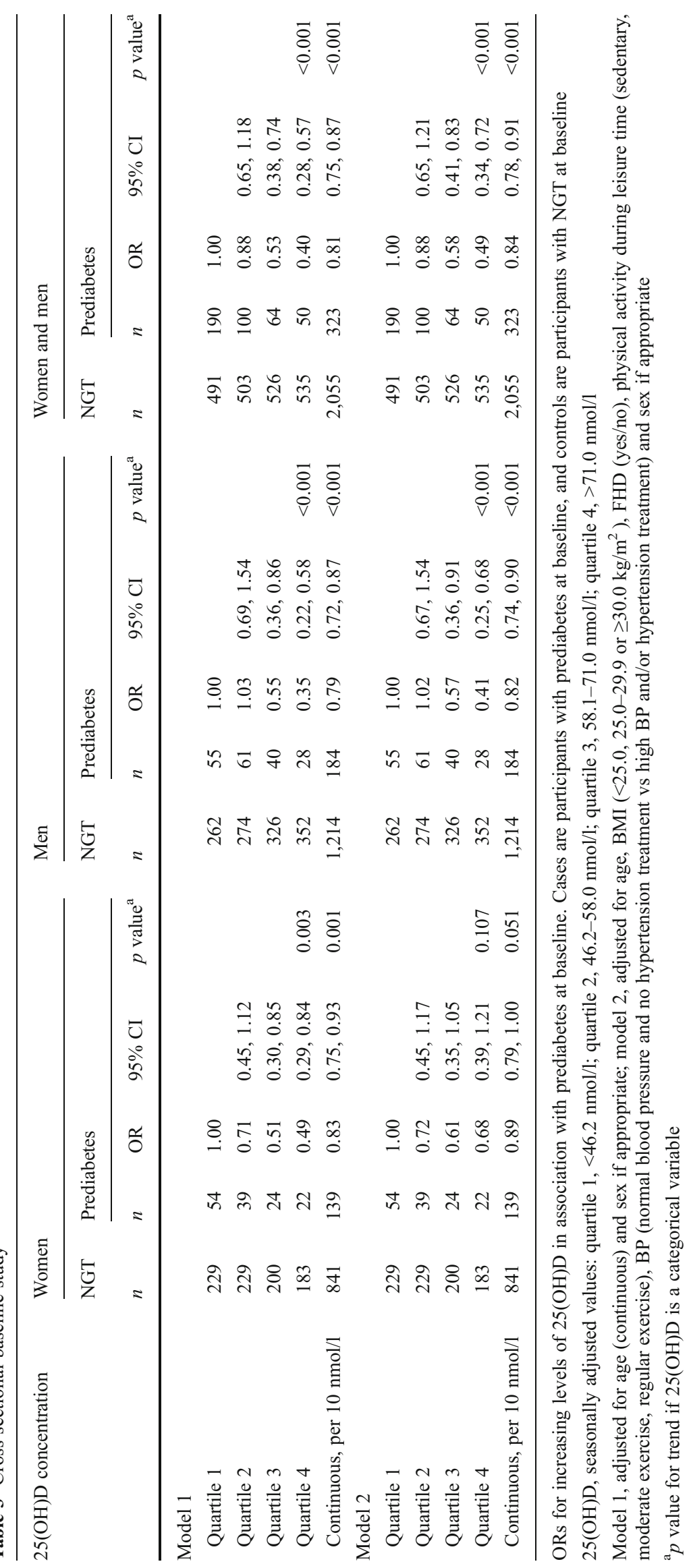




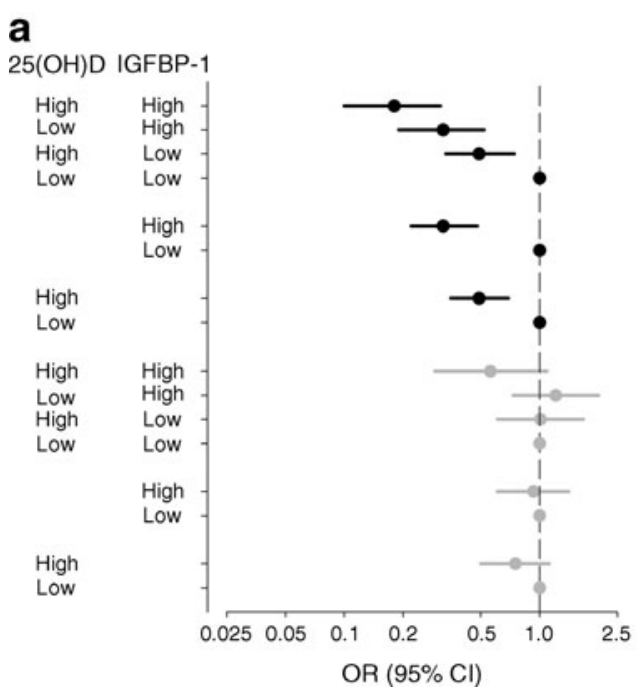

Fig. 2 Baseline serum levels of 25(OH)D and of IGFBP-1 (a) or IGF-I (b), separately and in combination, associated with prediabetes at baseline in women (grey lines) and men (black lines). Cases are participants with prediabetes at baseline, and controls are participants with NGT at baseline (cross-sectional study). Low, $<$ median; high, $\geq$ median. The seasonally adjusted median value for 25(OH)D was

overweight and physical inactivity may be critical in transforming the glucose tolerance status from normal to impaired. When prediabetes is already present, low serum 25 $(\mathrm{OH}) \mathrm{D}$ concentrations can promote a further deterioration in glucose tolerance.

There are several suggested mechanisms for how vitamin D might influence the progression from prediabetes to type 2 diabetes. Vitamin D receptors (VDRs) are expressed in more than 30 different tissues, including pancreatic islet and skeletal muscle cells [25], and serum vitamin D concentrations may exert modulating effects on both insulin secretion and insulin action [13-16]. The direct effect of vitamin D might be mediated by binding of the circulating active form, $1.25(\mathrm{OH}) \mathrm{D}_{3}$, to the pancreatic beta cell VDR, and activation of vitamin $\mathrm{D}$ within the beta cell by the 1- $\alpha$-hydroxylase enzyme; alternatively, it may be brought about by an effect on insulin action through stimulating the expression of insulin receptors and enhancing insulin responsiveness for glucose transport [2]. The indirect effects of vitamin D can be mediated via regulating extracellular calcium and insulin secretion through calcium fluxes in the beta cells [26]. Vitamin D may also be involved in systemic inflammation processes, and improve insulin sensitivity and promote beta cell survival by directly modulating the effect of cytokines [2]. Furthermore, polymorphisms in the VDR gene may also be linked to insulin resistance, insulin secretion and fasting glucose levels. The latter seems to be a less likely explanation for our findings, however, since there was no association between FHD and 25(OH)D concentration.

Although we found that the predictive value of serum 25 $(\mathrm{OH}) \mathrm{D}$ concentration as a continuous trait was similar in

\section{b}

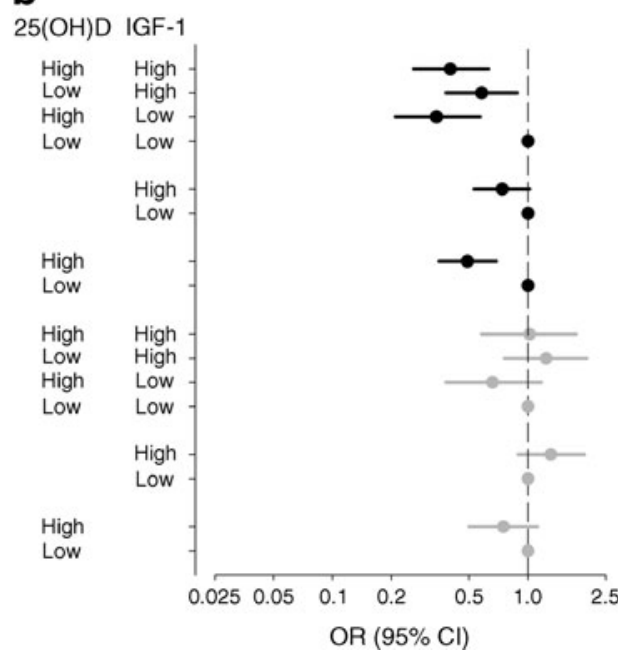

$58.1 \mathrm{nmol} / 1$ for both women and men; the median value of IGFBP-1 for women was $43 \mu \mathrm{g} / \mathrm{l}$ and for men was $25 \mu \mathrm{g} / \mathrm{l}$; and the median value of IGF-I was $192 \mu \mathrm{g} / \mathrm{l}$ for both women and men. Logistic regression was performed. The data are expressed as OR and $95 \%$ CI, adjusted for age, BMI, FHD, physical activity and BP measured at baseline

women and men, the categorical data demonstrated a sex difference implying a more obvious role of vitamin $\mathrm{D}$ in men than in women. This difference was evident in relation to both the value of serum $25(\mathrm{OH}) \mathrm{D}$ as a predictor of the risk of developing type 2 diabetes from prediabetes, and the association between $25(\mathrm{OH}) \mathrm{D}$ and prediabetes in the crosssectional study. Notably, these associations were also significant in women when adjusting only for age, but disappeared after full adjustment for possible confounders.

The major factor behind this adjustment effect appeared to be BMI, which seems to be a strong confounder in this context. Thus, serum $25(\mathrm{OH}) \mathrm{D}$ concentrations have been shown to be inversely correlated with various measures of obesity, including weight, BMI and waist circumference [27-29]. In a prospective Norwegian investigation, baseline serum 25(OH)D levels were inversely associated with type 2 diabetes after an 11-year follow-up, but this association disappeared in both sexes after adjustment for BMI [30]. Another factor that may influence the predictive value of vitamin $\mathrm{D}$ status in women is that there were rather few women with serum $25(\mathrm{OH}) \mathrm{D}$ concentrations in the higher quartiles and prediabetes who progressed to type 2 diabetes. Thus, it remains unclear whether our loss of significance in women after adjustment for BMI and other possible confounders is accounted for by a lack of power or any other factor.

In line with our previous reports, high IGFBP-1 concentrations predicted a reduced risk of diabetes in both men and women [17, 18], and these effects were evident regardless of $25(\mathrm{OH}) \mathrm{D}$ serum concentrations. Interestingly, in the presence of low serum IGFBP-1 concentrations, high $25(\mathrm{OH}) \mathrm{D}$ concentrations did not predict a reduced risk of progression to 
type 2 diabetes. Thus, these data do not support the findings of an earlier study by Forouhi et al. [9] demonstrating that high serum 25(OH)D concentrations were associated with improved glucose tolerance in participants with low, but not high, serum IGFBP-1 concentrations. High serum IGF-1 levels predicted a reduced risk of diabetes only in men, and there were no further significant effects due to $25(\mathrm{OH}) \mathrm{D}$ concentration. Thus, in agreement with Forouhi et al. [9], we were not able to present supporting evidence for a previous finding by Hypponen et al, in a British cohort [19], that high but not low serum concentrations of $25(\mathrm{OH}) \mathrm{D}$ combined with high serum IGF-1 levels are associated with a decreased risk of developing components of the metabolic syndrome. Interactions between the IGF system and vitamin D have been suggested [6, $31,32]$. Thus, serum $25(\mathrm{OH}) \mathrm{D}$ may regulate IGF-1 activity and, conversely, IGF-1 may increase vitamin D concentrations. Furthermore, vitamin $\mathrm{D}$ has been shown to stimulate IGFBP-1 production, probably via binding to VDRs [33].

In summary, high serum concentrations of $25(\mathrm{OH}) \mathrm{D}$ predict a reduced risk of progressing from prediabetes to type 2 diabetes. Furthermore, there was a cross-sectional association between prediabetes and serum $25(\mathrm{OH}) \mathrm{D}$ concentration, mainly in men. There were no significant interactions concerning diabetes risk between IGF-1 and IGFBP-1 on the one hand and $25(\mathrm{OH}) \mathrm{D}$ on the other. Our data suggest that vitamin D supplementation should be evaluated as for the prevention of type 2 diabetes in individuals with prediabetes.

Acknowledgments The skillful technical assistance of E. Sandberg and I.-L. Wivall (Department of Molecular Medicine and Surgery, Karolinska Institutet, Karolinska University Hospital, Stockholm, Sweden) is acknowledged.

Funding This study was supported by grants from the European Federation for the Study of Diabetes, the Swedish Research Council, the Swedish Heart-Lung Foundation, the Strategic Diabetes and Cardiovascular Programmes of Karolinska Institutet, the Stockholm County Council, the Swedish Diabetes Association, Novo Nordisk Scandinavia and Family Erling Persson Foundation.

Duality of interest The authors declare that there is no duality of interest associated with this manuscript.

Contribution statement All authors contributed to the study design, analysis and interpretation of data, drafting or revising the manuscript, and approved its final version.

\section{References}

1. Mathieu C, Gysemans C, Giulietti A, Bouillon R (2005) Vitamin D and diabetes. Diabetologia 48:1247-1257

2. Pittas AG, Lau J, Hu FB, Dawson-Hughes B (2007) The role of vitamin $\mathrm{D}$ and calcium in type 2 diabetes. A systematic review and meta-analysis. J Clin Endocrinol Metab 92:2017-2029
3. Holick MF (2007) Vitamin D deficiency. New Engl J Med 357:266-281

4. Scragg R (2008) Vitamin D and type 2 diabetes. Are we ready for a prevention trial? Diabetes 57:2565-2566

5. Holick MF (2008) Diabetes and the vitamin D connection. Curr Diabetes Rep 8:393-398

6. Boucher JB (2011) Vitamin D insufficiency and diabetes risks. Current Drug Targets 12:61-87

7. Mattila C, Knekt P, Maennistoe S et al (2007) Serum 25hydroxyvitamin D concentration and subsequent risk of type 2 diabetes. Diabetes Care 30:2569-2570

8. Knekt P, Laaksonen M, Mattila C et al (2008) Serum vitamin D and subsequent occurrence of type 2 diabetes. Epidemiology 19:666-671

9. Forouhi NG, Luan J, Cooper A, Boucher BJ, Wareham NJ (2008) Baseline serum 25-hydroxy vitamin $\mathrm{D}$ is predictive of future glycemic status and insulin resistance-the Medical Research Council Ely Prospective Study 1990-2000. Diabetes 57:26192625

10. Pittas AG, Sun Q, Manson JE, Dawson-Hughes B, Hu FB (2010) Plasma 25-hydroxyvitamin D concentration and risk of incident type 2 diabetes in women. Diabetes Care 33:2021-2023

11. Liu E, Meigs JB, Pittas AG et al (2010) Predicted 25hydroxyvitamin $\mathrm{D}$ score and incident type 2 diabetes in the Framingham Offspring Study. Am J Clin Nutr 91:1627-1633

12. Gagnon C, Lu ZX, Magliano DJ et al (2011) Serum 25hydroxyvitamin $\mathrm{D}$, calcium intake, and risk of type 2 diabetes after 5 years. Diabetes Care 34:1133-1138

13. Teegarden D, Donkin SS (2009) Vitamin D: emerging new roles in insulin sensitivity. Nutrition Res Rev 22:82-92

14. Alvarez JA, Ashraf A (2010) Role of vitamin D in insulin secretion and insulin sensitivity for glucose homeostasis. Int J Endocrinol 2010:351385. doi:10.1155/2010/351385:1-18

15. Kayaniyil S, Vieth R, Retnakaran R et al (2010) Association of vitamin $\mathrm{D}$ with insulin resistance and beta-cell dysfunction in subjects at risk for type 2 diabetes. Diabetes Care 33:13791381

16. Mitri J, Dawson-Hughes B, Hu FB, Pittas AG (2011) Effects of vitamin $\mathrm{D}$ and calcium supplementation on pancreatic $\beta$ cell function, insulin sensitivity, and glycemia in adults at high risk of diabetes: the Calcium and Vitamin D for Diabetes Mellitus (CaDDM) randomized controlled trial. Am J Clin Nutr 94:486494

17. Lewitt MS, Hilding A, Ostenson CG, Efendic S, Brismar K, Hall K (2008) Insulin-like growth factor-binding protein-1 in the prediction and development of type 2 diabetes in middle-aged Swedish men. Diabetologia 51:1135-1145

18. Lewitt MS, Hilding A, Brismar K, Efendic S, Ostenson CG, Hall K (2010) IGF-binding protein 1 and abdominal obesity in the development of type 2 diabetes in women. Eur J Endocrinol 163:233242

19. Hypponen E, Boucher BJ, Berry DJ, Power C (2008) 25hydroxyvitamin D, IGF-1, and metabolic syndrome at 45 years of age. A cross-sectional study in the 1958 British birth cohort. Diabetes 57:298-305

20. Eriksson AK, Ekbom A, Granath F, Hilding A, Efendic S, Ostenson CG (2008) Psychological distress and risk of prediabetes and type 2 diabetes in a prospective study of Swedish middle-aged men and women. Diabetic Med 25:834-842

21. American Diabetes Association (2004) Diagnosis and classification of diabetes mellitus. Diabetes Care 27:S5-S10

22. Shankar A, Sabanayagam C, Kalidindi S (2011) Serum 25hydroxyvitamin D levels and prediabetes among subjects free of diabetes. Diabetes Care 34:1114-1119

23. Barengolts E (2010) Vitamin D role and use in prediabetes. Endocrine Pract 16:476-485 
24. Baz-Hecht M, Goldfine AB (2010) The impact of vitamin D deficiency on diabetes and cardiovascular risk. Curr Opin Endocrinol Diabetes Obes 17:113-119

25. Zittermann A (2003) Vitamin D in preventive medicine: are we ignoring the evidence? Br J Nutr 89:552-572

26. Davidson HW, Rhodes CJ, Hutton JC (1988) Intraorganellar calcium and $\mathrm{pH}$ control proinsulin cleavage in the pancreas beta cell via two distinct site-specific endopeptidases. Nature 333:93-96

27. Bell NH, Epstein S, Greene A, Shary J, Oexmann MJ, Shaw S (1985) Evidence for alteration of the vitamin-D-endocrine system in obese subjects. J Clin Invest 76:370-373

28. Liel Y, Ulmer E, Shary J, Hollis BW, Bell NH (1988) Low circulating vitamin-D in obesity. Calcified Tissue Int 43:199-201

29. Macdonald HM, Mavroeidi A, Barr RJ, Black AJ, Fraser WD, Reid DM (2008) Vitamin D status in postmenopausal women living at higher latitudes in the UK in relation to bone health, overweight, sunlight exposure and dietary vitamin D. Bone 42:996-1003
30. Grimnes G, Emaus N, Joakimsen RM et al (2010) Baseline serum 25-hydroxyvitamin D concentrations in the Tromso Study 1994 95 and risk of developing type 2 diabetes mellitus during 11 years of follow-up. Diabet Med 27:1107-1115

31. Schernhammer ES, Hankinson SE, Hunter DJ, Blouin MJ, Pollak MN (2003) Polymorphic variation at the -202 locus in IGFBP3: influence on serum levels of insulin-like growth factors, interaction with plasma retinol and vitamin $\mathrm{D}$ and breast cancer risk. Int $\mathrm{J}$ Cancer 107:60-64

32. Gomez JM, Maravall FJ, Gomez N, Navarro MA, Casamitjana R, Soler J (2004) Relationship between $25-(\mathrm{OH}) \mathrm{D}_{3}$, the IGF-1 system, leptin. Anthropometric and body composition variables in the healthy randomly selected population. Horm Metab Res 36:48-53

33. Parikh G, Varadinova M, Suwandhi P et al (2010) Vitamin D regulates steroidogenesis and insulin-like growth factor binding protein-1 (IGFBP-1) production in human ovarian cells. Horm Metab Res 42:754-757 